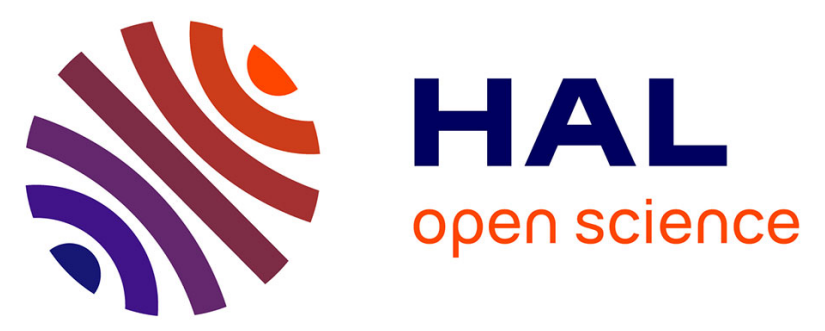

\title{
Motivational interviewing as a way to promote physical activity in obese adolescents: A randomised-controlled trial using self-determination theory as an explanatory framework
}

Mathieu Gourlan, Philippe Sarrazin, David Trouilloud

\section{To cite this version:}

Mathieu Gourlan, Philippe Sarrazin, David Trouilloud. Motivational interviewing as a way to promote physical activity in obese adolescents: A randomised-controlled trial using self-determination theory as an explanatory framework. Psychology and Health, 2013, 28 (11), pp.1265-1286. 10.1080/08870446.2013.800518 . hal-00947430

\author{
HAL Id: hal-00947430 \\ https://hal.science/hal-00947430
}

Submitted on 17 May 2014

HAL is a multi-disciplinary open access archive for the deposit and dissemination of scientific research documents, whether they are published or not. The documents may come from teaching and research institutions in France or abroad, or from public or private research centers.
L'archive ouverte pluridisciplinaire HAL, est destinée au dépôt et à la diffusion de documents scientifiques de niveau recherche, publiés ou non, émanant des établissements d'enseignement et de recherche français ou étrangers, des laboratoires publics ou privés. 
1 Motivational interviewing as a way to promote physical activity in obese adolescents: A

2 randomized-controlled trial using self-determination theory as an explanatory framework

3

4

5

6

7

8

9

10

11

12

13

14
Gourlan Mathieu

Sarrazin Philippe

Trouilloud David

Univ. Grenoble Alpes, SENS, F-38041 Grenoble

Mathieu GOURLAN: Univ. Grenoble Alpes, Laboratoire SENS, 38041 Grenoble_- France.

Phone: +33 476635 094. E-mail: mathieugourlan@yahoo.fr

(corresponding author) Philippe SARRAZIN: Univ. Grenoble Alpes, Laboratoire SENS,

38041 Grenoble - France. Phone: +33 476635 094. E-mail:philippe.sarrazin@ujf-

grenoble.fr

(corresponding author) David TROUILLOUD: Univ. Grenoble Alpes, Laboratoire SENS, 38041 Grenoble - France. Phone: +33 476635 094. E-mail: david.trouilloud@ujf-grenoble.fr

Psychology and Health, In Press (2013)

DOI:10.1080/08870446.2013.800518 
2 Using Self-Determination Theory (SDT; Deci \& Ryan, 2002) as an explanatory framework,

3 this randomized-controlled study evaluates the effect of a motivational interviewing-based

4 intervention (MI; Miller \& Rollnick, 2002) as an addition to a standard weight loss program

5 (SWLP) on physical activity (PA) practice in obese adolescents over a 6-month period. Fifty-

6 four obese adolescents (mean age $=13$ years, mean BMI $=29.57 \mathrm{~kg} / \mathrm{m}^{2}$ ) were randomly

7 assigned to an SWLP group $(n=28)$ or SWLP + MI group $(n=26)$. Both groups received two

8 SWLP sessions, supplemented for the SWLP + MI group, by 6 MI sessions. Perceived

9 autonomy support, perceived competence, motivational regulations, PA and BMI were

assessed at baseline, 3- and 6-months (i.e., the end of the program). MLM analyses revealed

that compared to SWLP, the SWLP + MI group had a greater BMI decrease and a greater PA

12 practice increase over time. Moreover, the SWLP + MI group reported greater autonomy

support from medical staff at the end of the program, greater increase in integrated and

14 identified regulations, and a stronger decrease in amotivation. MI appears as an efficient

15 counseling method as an addition to an SWLP to promote PA in the context of pediatric

16 obesity.

17 Running title: Motivational interviewing and adolescent obesity

18 Key-words: Motivational interviewing, Self-determination theory, Obesity, Adolescence, 
Motivational interviewing as a way to promote physical activity in obese adolescents: A randomized-controlled trial using self-determination theory as an explanatory framework

\section{Introduction}

Adolescent obesity is a major public health problem that has increased at a dramatic pace over the last few years (Lobstein, Baur, \& Uauy, 2004). Ten percent of the school-aged children in the world are presently considered as overweight (Lobstein et al., 2004). Such a trend is disturbing given the physical (e.g., type 2 diabetes) and psychosocial (e.g., low selfesteem) risks associated with overweight during adolescence (Reilly, 2007). Thus, the management of pediatric obesity and weight control appears as a health priority. Regular physical activity (PA) is one of the key elements in the management of adolescent obesity, along with changes in eating behavior (Parizkova \& Hills, 2001). Moreover, in addition to its important role in the maintenance of weight loss, PA may also improve cardiovascular fitness and psychological well-being (Reilly, 2007).

Despite the well-known benefits of regular PA, obese adolescents tend to adopt a less active lifestyle than their non-obese counterparts. Specifically, some studies (e.g., Olds, Ferrar, Schranz, \& Maher, 2011) report a daily PA practice shorter by 20 minutes. Recent reviews and meta-analysis (Cliff, Okely, Morgan, Jones, \& Steele, 2010; Gourlan, Trouilloud, \& Sarrazin, 2011) revealed that although interventions implemented to promote PA in obese populations demonstrated positive effects on average, there is a high variability in the effectiveness between these studies (Gourlan et al., 2011). Moreover, the explicative processes involved in the behavioral changes generated by those interventions remain largely unknown (Annesi \& Withaker, 2010). It thus seems important to (1) continue to identify the characteristics of efficient interventions promoting PA among this population, and (2) better understand the psychosocial factors involved during those interventions. 
Motivational interviewing (MI) is nowadays considered as a suitable approach to promote health behaviors (Rollnick, Miller, \& Butler, 2008). The primary purpose of this study was to assess the effectiveness of an MI-based intervention in addition to a standard weight loss program (SWLP) on PA and body mass index (BMI) of obese adolescents. Moreover, drawing upon Self-Determination Theory (SDT; Deci \& Ryan, 2002), the second purpose was to explore some of the underlying motivational processes accompanying these effects. The next section presents the main postulates of MI and SDT and their interest for understanding PA and health behavior change among obese adolescents.

\section{Motivational Interviewing: a promising approach to promoting physical activity}

MI can be defined as a "collaborative, person-centered form of guiding to elicit and strengthen motivation for change" (Miller \& Rollnick, 2009, p. 137). Its goal is to create an atmosphere in which the patient, rather than the counselor, becomes the main advocate for change as well as the primary agent for change. Expressing empathy (i.e., the counselor's attitude of acceptance), developing discrepancy (i.e., amplifying discrepancy between the patient's present behavior and his/her important goals), avoiding argumentation (i.e., assuming that the patient is responsible for change), rolling with resistance (i.e., acknowledging and exploring the patient's arguments against changing) and supporting selfefficacy (i.e., helping the patient to find resources to implement new behaviors and overcome barriers) are the general principles upon which MI is based (see Miller \& Rollnick, 2002).

Research globally supports the view that MI provides a promising framework for enhancing adherence to health behaviors. Meta-analyses report medium-to-large effects of MI on treatment adherence and small-to-medium effects on treatment outcomes (e.g., drug consumption, psychological well-being) (Hettama, Steele, \& Miller, 2005; Lundhal, Kunz, Brownell, Tollefson, \& Burke, 2010). Regarding weight loss, MI has also been recognized as an efficient approach among adults to improve PA and regime adherence (e.g., Hardcastle, 
1 Taylor, Bailey, \& Castle, 2008) as well as reduce body mass in obese populations (Armstrong

2 et al., 2011). Some authors have suggested that MI could also be a promising approach for

3 pediatric obesity (Resnicow, Davis, \& Rollnick, 2006). However, the impact of MI among

4 obese adolescents has received very little attention in the scientific literature. Despite some

5 promising results on eating habits (MacDonell, Brogan, Naar-King, Ellis, \& Marshall, 2012),

6 the effectiveness of MI on health behaviors such as PA for this population still has to be

7 determined.

8 Self-determination theory: a heuristic framework for understanding health behavior 9 change

SDT (Deci \& Ryan, 2002) is a broad psychological theory of motivation particularly suited to understand health behavior (see $\mathrm{Ng}$ et al., 2012, for a review). One of its basic tenets is that human motivation varies in the extent to which it is autonomous (when individuals engage in a behavior with a full sense of volition and choice) or controlled (when individuals engage in a behavior while experiencing internal or external pressure) along a continuum. Identified regulation (i.e., engaging in an activity because it is perceived as personally important and useful), integrated regulation (i.e., engaging in an activity because it is perceived as coherent with his/her values and identity) and intrinsic motivation (i.e., engaging in an activity because of the inherent satisfaction it conveys) represent increasingly autonomous forms of motivation. In contrast, introjected regulation (i.e., engaging in an activity to avoid negative emotions such as anxiety or guilt), external regulation (i.e., engaging in an activity to obtain a tangible reward, to avoid a punishment or to comply with an external authority) represent increasingly controlled forms of motivation. In addition to autonomous and controlled forms of motivation, SDT also considers amotivation (i.e., individuals see no relationship between behavior and outcomes) which represents the absence of motivation (see Deci \& Ryan, 2002). 
While the differentiation between autonomous versus controlled motivation is central to

2 SDT, perceived competence (i.e., individuals' feeling of efficacy with respect to the behavior)

3 is an important variable of the theory too presumed to facilitate autonomous motivation (Deci

4 \& Ryan, 2002). Furthermore, SDT suggests that the social context - in particular, the degree

5 of autonomy support provided by healthcare supervisors (i.e., active listening, collaboration,

6 respect and thorough support) - may improve patients' autonomous motivation, perceived

7 competence and health-relevant behaviors (Patrick \& Williams, 2012). Research has shown

8 that perceived autonomy support, autonomous forms of motivation and perceived competence

9 are related to positive health outcomes (see $\mathrm{Ng}$ et al., 2012, for a review), such as a reduction

10 in BMI (Silva et al., 2010) and an increase in PA among obese or overweight patients (Fortier,

11 Sweet, O’Sullivan, \& Williams, 2007; Silva et al., 2010).

\section{The present study}

The primary purpose of this study was to evaluate the effectiveness of an MI-based intervention as an addition to a standard weight loss program (SWLP) in order to improve PA and BMI in obese adolescents. Based on the transmission of knowledge and skills to generate behavior change (Cooper, Fairburn, \& Hawker, 2003), SWLP has been found to have a positive - but modest - impact on PA and BMI of obese adolescents (Gilles, Cassano,

Shepherd, Higgins, Hecker, \& Nangle, 2008). One of the viable explanations is that this kind of intervention does not formally address ambivalence about change. Sustained motivation for PA may yet be especially difficult for obese participants (Gourlan, Trouilloud, Sarrazin, in press). That is why the addition of MI could be valuable during an SWLP because it could increase participants' self-determined motivation toward PA when motivational barriers arise and thus complement the acquisition of behavioral change skills (e.g., Burke, 2011; Westra \& Arkowitz, 2011). A recent meta-analysis on adult obesity pointed out that the addition of MIbased sessions to weight-loss interventions has a beneficial impact on treatment outcomes 
1 (Armstrong et al., 2011). As very few studies have dealt with the impact of MI on obesity

2 management in adolescents (i.e., MacDonell et al., 2012), less is known about the potential

3 benefits of this strategy, and its complementarity with SWLP, among this population. The

4 participants of this study were randomly assigned to a group participating in an SWLP

5 (SWLP group) or to a group receiving the same SWLP supplemented with 6 phone MI

6 sessions oriented toward the promotion of PA (SWLP + MI group). Recent research reported

7 that phone may be an interesting media to implement MI, particularly in order to limit time

8 constrains or transportation problems for participants (van Keulen et al., 2011). While both

9 groups were expected to benefit from the intervention received, it was hypothesized that

10 adolescents in the SWLP + MI group would report a greater increase in PA and a greater

11 decrease in BMI over time as compared to those in the SWLP group.

12 Based on SDT tenets, the second purpose was to explore some potential mechanisms

13 involved in the changes generated by the interventions, in particular perceived autonomy

14 support, motivational regulations and perceived competence. Because an SWLP is based on

15 the promotion of skills and knowledge of health behaviors, it is believed to promote perceived

16 competence (Annesi \& Withaker, 2010). Thus, it was hypothesized that adolescents in both

17 groups would report an increase in perceived competence over time. However, because MI is

18 specifically designed to support perceived competence, the increase was expected to be

19 greater in the SWLP + MI group. In addition, as advocated by some scholars (e.g., Markland

20 et al., 2005; Vansteenkiste \& Sheldon, 2006), the MI intervention should improve

21 autonomous forms of motivation, notably by supporting participant autonomy. The four MI

22 principles presented above should generate an autonomy-supportive climate, thus promoting

23 autonomous motivation and hindering amotivation toward PA. Thus, it was hypothesized that

24 adolescents in the SWLP + MI group would report (1) higher perceptions of autonomy 
1 support, (2) greater increase in autonomous forms of motivation, and (3) greater decrease in

2 amotivation over time as compared to those in the SWLP group.

\section{Methods}

$4 \quad$ Study Design

Power analysis, assuming an effect size of $d=0.74$ (Hettema et al. 2005), a power of

$680 \%$ and an alpha level of 0.05 , indicated an average sample size of 30 participants per

7 condition. Sixty-two obese adolescents ( $41 \%$ female) were thus recruited over a two-year

8 period in a French hospital. All had been referred to the hospital by their general practitioner

9 because of their extreme obesity. Eligible participants were between the ages of 11 and 18

10 years old (Mean age $=13, \mathrm{SD}=1.66$ ), had a BMI over the $90^{\text {th }}$ age and gender specific

percentiles (Mean $\left.\mathrm{BMI}=29.57 \mathrm{~kg} / \mathrm{m}^{2}, \mathrm{SD}=5.34\right)$, and did not have any unstable or

uncontrollable diseases. Judgment of eligibility of the adolescents was made by the healthcare

provider of the study (see below) and was done without foreknowledge of the randomization

14 sequence. The project manager assigned each adolescent randomly and independently to the

15 SWLP group $(n=34)$ or the SWLP + MI group $(n=28)$ (see figure 1 for the CONSORT

16 flowchart of participants). Participants, the health care provider and data collectors were

17 blinded to the group (SWLP or SWLP+MI) the adolescents were assigned to. The study was

18 approved by the research ethics committee of the specific academic institution. Parents

19 provided informed consent, and adolescents provided written assent for study participation.

In the SWLP group, participants received an intervention consisting of 2 individual

21 face-to-face sessions of 30 minutes at the hospital with a healthcare provider over a three-

22 month period. In the MI condition, participants received the same intervention by the same healthcare provider plus $6 \mathrm{MI}$ phone sessions with a PA trained counselor of 20 minutes over

24 a 6-month period (3 MI between the two SWLP sessions and 3 after the last SWLP session). 
2 obesity and certified in Behavioral and Cognitive Therapies. The goal was to promote a

3 balance diet, a healthy lifestyle and PA. The Healthcare provider led the session by providing

4 and transmitting knowledge and skills. Logical and rational arguments can be used to

5 convince the adolescent to adopt new behaviors. The main 'active ingredients' of this

6 intervention listed in the CALO-RE taxonomy (Michie Ashford, Sniehotta, Dombrowski,

7 Bishop, \& French, 2011) consisted of: providing information on consequences of behavior in

8 general (e.g., relationship between PA and physical and mental health, based on

9 epidemiological studies), providing information on consequences of behavior to the individual (e.g., benefits and costs of doing or not doing PA on weight loss among obese adolescents), prompting goal setting (behavior) (e.g., 30 minutes of PA per day, five or more days per week), providing information on where and when to perform the behavior (e.g., tips on places and times adolescent can do PA), prompting self-monitoring of behavior (e.g., self-monitoring habitual weekly PA), and providing feedback on behavior (e.g., comparing current PA practice with recommendations).

MI. A sport and exercise sciences doctoral student delivered MI sessions. He received 17 an MI training including 40 hr of reading (Arkowitz, Westra, Miller, \& Rollnick, 2008; Miller \& Rollnick, 2002; Rollnick et al., 2008) and 32 hours of training formation with the French Association of Motivational Interviewing. The main 'active ingredient' of this intervention consisted of MI, namely to elicit and reinforce the adolescent's change talk in order to

21 minimize resistance and resolve ambivalence to change (Michie et al., 2011). For each

22 session, the four MI principles developed above and basic techniques (e.g., using open-ended questions, affirming the patient's freedom of choice) were used to encourage adolescents to articulate their concerns and goals, and develop their autonomy (Miller \& Rollnick, 2002). 
1 Sessions followed a semi-structured format and were likely to include the four following

2 aspects (see Appendix 2 for a further presentation of MI intervention).

3 Phase 1, making the participant's acquaintance and building awareness: The counselor's role

4 was to elicit the participant's thoughts and increase his/her awareness of them. First, the

5 counselor aimed to create a confident relationship by discussing what was important in the

6 participant's life (e.g., hobbies, friends, projects for the future). Second, the counselor

7 introduced weight and PA-related concerns (e.g., body image, present PA practice). Change

8 talk was encouraged by exploring ambivalence and conflicting beliefs about behavior change.

9 Phase 2, Alternatives and problem solving: Once the adolescent had begun to evoke the discomfort of the present situation and the possibility, the necessity or the importance of making some change(s), alternatives to current behaviors were considered. All options were

behaviors were selected depending on the participant's needs and aspirations.

Phase 3, Goal setting and agenda setting: When alternative behavior had been chosen, the counselor and participant set some goals that were realistic and achievable. Potential barriers to accomplishing the plan and strategizes to overcome these barriers were also discussed.

Phase 4, Behavior modification consequences and perspectives: Behavior adoption consequences (e.g., unexpected barriers, feelings toward behavior) were considered. Finally, behavior maintenance and possibilities of adopting new PA habits were also discussed.

MI integrity. All MI sessions were audio-taped. To assess fidelity to MI principles, 25 randomly selected interviews were evaluated by a Sport and Exercise Sciences doctoral student trained in the Motivational Interviewing Treatment Integrity code, Version 3.1.1

(MITI; Moyers, Martin, Manuel, Miller, \& Ernst, 2010). Percent complex reflections (CR), percent open-ended questions (OC), reflection-to-question ratio (R:Q), percent MI adherent (MiA) and a Global MI Spirit rating (GMIS) were calculated (the last indicator with a 5-point 
1 scale). Means for the behavioral counts were as follows: $\mathrm{CR}=40.65(\mathrm{SD}=13.12), \mathrm{OQ}=$

$254.58(\mathrm{SD}=12.99), \mathrm{R}: \mathrm{Q}=0.78(\mathrm{SD}=0.36), \mathrm{MiA}=86.57(\mathrm{SD}=16.31)$. Mean for GMIS was

$3 \quad 3.76(\mathrm{SD}=0.47)$. Scores were above proficiency guidelines for $\mathrm{CR}, \mathrm{OQ}, \mathrm{GMIS}$, and slightly

4 below proficiency for R:Q and MiA (see Moyers et al., 2010).

5 Assessment intervals

Perceived competence, motivation for PA and self-reported PA were administered

7 three times: at baseline, 3- and 6-months. At 6 months participants also completed a

8 questionnaire about perceived autonomy support from medical staff during the intervention.

9 Because self-reported PA is deemed to be biased in this population (Buchowski, Townsend,

Chan, Acra, \& Sun, 1999), a randomized subsample of adolescents wore an accelerometer for

one week to assess PA at the baseline and at 6 months. Combining objective measures with

self-report of PA is believed to achieve greater measurement accuracy (Cliff et al., 2010).

\section{Measurement}

Motivations for PA. Motivation for PA was assessed with a French version of the Behavioral Regulation Exercise Questionnaire (BREQ-2) (Markland \& Tobin, 2004). This 20-item scale assesses the reasons why people exercise or participate in PA. The BREQ-2 includes subscales assessing intrinsic (e.g., "I exercise because it's fun"), identified (e.g., "I think it is important to make the effort to exercise regularly"), introjected (e.g., "I feel guilty when I don't exercise"), external (e.g., "I take part in exercise because my friends/family say I should") regulations, and amotivation (e.g., "I don't see why I should have to exercise").

Following the stem "Why do you engage in exercise?" participants respond to each item on a

22 7-point scale ranging from 1 ("not true for me") to 7 ("very true for me"). In addition, integrated regulation was assessed through 4 items (e.g., "I consider exercise to be part of my identity"; Wilson, Rodgers, Loitz, \& Scime, 2006). Previous research supports the BREQ-2's 
1 Tobin, 2004; Wilson et al., 2006).

2 Perceived competence. Perceived competence was measured using a scale that was created

3 based on recommendations by Bandura (1997). This four-item questionnaire assesses

4 participants' degree of confidence in their ability to complete at least 30 minutes of moderate-

5 intensity activity at frequencies of one, two, three, and four occasions per week. For each item

6 the participants recorded the strength of their self-efficacy beliefs on a 100-point scale using a

7 scale ranging from $0 \%$ ("absolutely not confident") to $100 \%$ (“absolutely confident"),

8 increasing in ten-point increments. A perceived competence toward exercise score was

9 calculated by averaging the answers to the four items.

Perceived autonomy support. At 6-months, participants completed a French version of the

11 Health Care Climate Questionnaire (HCCQ) (Fortier et al., 2007) to assess perceived

12 autonomy support from the medical staff during the intervention. Participants responded to 6

13 items (e.g., "I feel that healthcare providers in the hospital provided me with choices and

14 options about PA") on a 7-point Likert scale ranging from 1 ("strongly disagree") to 7

15 ("strongly agree"). "Medical staff" represented the healthcare provider in the SWLP condition

16 and both the healthcare provider and MI counselor in the SWLP + MI condition. Reliability

17 and validity of the HCCQ has been demonstrated in previous studies (e.g., Fortier et al.,

18 2007).

Self-reported PA. Self-reported PA was assessed using the 7-day PA recall interview (Gross,

20 Sallis, Buono, Roby, \& Nelson, 1990). The interviewer ascertained the participants' estimated

21 duration in activities of low, moderate, high and very high intensity, during the previous

22 week. Total PA length was calculated by adding the PA duration for each intensity level (in

hours per day). Total energy expenditure (in kilocalories) was calculated by multiplying each 
1 hard intensity, and 10 for very hard intensity). The reliability and validity of the 7-day PA

2 recall have been established elsewhere (e.g., Pereira et al., 1997).

3 Objective PA. Objective measurement of total energy expenditure (in kilocalories per day),

4 and length (in hours per day) associated with PA was done via an accelerometer, the

5 SenseWear® Pro2 Armband (BodyMedia, INC., PA, USA). The validity of this

6 accelerometer's suitability for estimating the PA of adolescents has been reported elsewhere

7 (e.g., Welk, McClain, Eisenmann, \& Wickel, 2007). Because of the methodological

8 unwieldiness of accelerometer use, a randomized subsample 20 adolescents were asked to

9 wear an accelerometer (10 in the SWLP + MI group and 10 in the SWLP group). At the

10 baseline and at 6-months they were instructed to wear it continuously, including during sleep,

11 for 3 consecutive days (i.e., two weekdays and one weekend day), except while showering or

12 swimming. Previous work indicates that 3 days appears as an acceptable sampling period for

13 an accelerometer (e.g., Trost, McIver, \& Pate, 2005). After removing incomplete data (e.g.,

14 incomplete wear-time and breakdown), 15 adolescents effectively wore the accelerometer (6

15 in the SWLP + MI group and 9 in the SWLP group).

16 Body mass index. BMI was calculated as body weight (in kilograms) divided by height (in

17 meters, squared). Body weight was recorded with the adolescents wearing light clothes and

18 without shoes (digital balance scale; Tanita ${ }^{\circledR}$ ModelBC-532) to the nearest $0.1 \mathrm{~kg}$. Height was

19 measured to the nearest $0.5 \mathrm{~mm}$ using a wall-mounted stadiometer (Seca ${ }^{\circledR}$ ). BMI is accepted

20 as a valid and suitable index for the assessment of obesity over time among children and

21 adolescents (Cole, Faith, Pietrobelli, \& Heo, 2005).

22 Statistical analyses

23 First, independent samples t-tests were carried out to evaluate whether the MI and

24 SWLP groups had differences at baseline on psychosocial, behavioral and demographic

25 variables. All primary outcomes analyses are based on an intention to treat analysis, with all 
1 adolescents included in the condition they were assigned. Then, various analyses were

2 conducted to test differences between conditions at the different measurement points.

3 Multilevel modeling (MLM) analyses were preferred when possible because they are

4 considered as particularly useful for the analysis of longitudinal data including at least 3

5 measurements nested within individuals (Steele, 2008). Such analyses were used for testing

6 changes in motivational regulations, perceived competence, self-reported PA, and BMI.

7 Repeated measure of variance (ANOVA) or independent samples t-tests were conducted

8 when variables were assessed once (i.e., perceived autonomy support) or twice (i.e., objective

9 PA).

Healy, Cameron, \& Charlton, 1999). As with standard regression analyses, the aim of MLM is

to express the dependent variable as a function of predictor variables. However, MLM can incorporate two levels of analyses: a within-person equation (Level 1), which concerns over time within-individual change, and a between-person equation (Level 2), which concerns inter-individual differences in change (i.e., that predicts differences between individuals in their rate of change over time) (Steele, 2008). Indeed, for each variable with 3 measurements

17 (i.e., self-reported PA, BMI, motivational regulations, perceived competence) a conditional growth model was tested to examine the effects of experimental condition (a dummy variable was created where SWLP $=0$ and SWLP + MI = 1) on the intercept and rate of change (i.e., the slope). In these models, the slope represents the change in the dependent variables scores

21 in the SWLP group, whereas the interaction between the slope and condition shows the 22 difference in the rate of change of scores between the SWLP and the SWLP + MI groups over the 6 months. Time measure was centered at month 6 . Consequently, the intercept reflects the mean level of the dependent variable at month 6 for the SWLP group, whereas the main effect for condition represents the difference in scores between the two conditions. 


\section{Results}

2 Attrition analysis and missing data

3 Fifty-four (28 in the SWLP group, 26 in the SWLP + MI group) participants

4 completed the interventions (attrition rate $=13 \%$ ) (see Figure 1 for the CONSORT flowchart

5 of participants). Among the completers, three missing data (i.e., participants not completing

6 all assessments) were identified. This did not appear as a concern given that MLM allows for

7 missingness on some variables, assuming data are missing at random (Steele, 2008). T-tests

8 and chi-square tests revealed that dropouts did not differ from completers with regard to

9 gender, BMI, motivational regulations, perceived competence and PA $\left(p_{s}>, 05\right)$. Dropouts

10 were, however, significantly older (Mean age $=14$ vs. 12.5 for dropouts and completers

11 respectively; $p<.01)$.

12 Baseline differences between groups and descriptive statistics group reported lower PA length and energy expenditure at the baseline $\left(p_{s}<.05\right)$. completers $(\mathrm{n}=54)$ (see Table 1$)$.

\section{Change in $B M I$}

MLM analyses revealed that participants in the SWLP group did not report significant change over time for BMI $(p=.47)$. As compared to those in the SWLP group, participants in the SWLP + MI group demonstrated a significant decrease for BMI $(\mathrm{B}=-0.89, p<.001, d=$ 
1 .59). However, they did not differ from the SWLP group on this variable at the end of the

2 intervention $(p=.17)$ (see Figure 2).

3 Change in $P A$

4 Concerning self-reported PA, MLM analyses ${ }^{1}$ revealed no change among participants

5 in the SWLP group for PA length (hours per day) $(p=.22)$ and energy expenditure

6 (kilocalories per day) $(p=.91)$. As compared to those in the SWLP group, participants in the

7 SWLP + MI group reported a significant increase over time for both PA length $(\mathrm{B}=2.75, p<$

$8 \quad .001, d=.57)$ and energy expenditure $(\mathrm{B}=135.22, p<.001, d=.38)$. Moreover, they

9 reported higher levels of $\mathrm{PA}$ length $(\mathrm{B}=3.31, p<.01, d=.39)$ and energy expenditure $(\mathrm{B}=$

$2.64, p<.01, d=.36$ ) than the SWLP group at 6 months (see Figure 2).

Concerning objective $\mathrm{PA}^{2}$, repeated measure ANOVAs revealed significant time $\times$

group interaction for PA length $[F(1,13)=4.5, p<.05, d=1.11]$, and PA energy expenditure $[F(1,13)=4.92, p<.05, d=1.16]$. Fisher's LSD post-hoc analyses revealed that contrary to the SWLP group, the SWLP + MI group increased its total PA length and energy expenditure over time $(p s<.001)$ (see Table 1$)$.

\section{Change in motivational regulations}

Concerning autonomous forms of motivation, MLM analyses revealed a significant increase in intrinsic motivation for the SWLP group $(\mathrm{B}=0.22, p<.05, d=.57)$. No differential change over time was found for the SWLP + MI group as compared to the SWLP group $(p=.87)$, suggesting a similar increase for both groups on this variable. At 6 months, participants of the two groups did not differ on this variable $(p=.08)$. Moreover, participants in the SWLP group reported no significant change for integrated regulation $(p=.98)$ and identified regulation $(p=.92)$. As compared to those in the SWLP group, participants in the SWLP + MI group reported a significant increase over time for both integrated $(B=0.39$, $p<.01, d=.43)$ and identified regulations $(\mathrm{B}=0.33, p<.01, d=.36)$. Moreover, they 
1 reported significant higher levels of integrated $(\mathrm{B}=0.8, p<.001, d=.34)$ and identified

2 regulations $(\mathrm{B}=0.67, p<.01, d=.31)$ at 6 months, compared to the participants in the SWLP

3 group (see Figure 2 for results related to identified and integrated regulations).

4

Concerning controlled forms of motivation, no significant changes were found for the SWLP group on introjected $(p=.69)$, and external regulations $(p=.69)$. No differential effect was found for the SWLP + MI group as compared to the SWLP group on those two motivational regulations ( $p=.43$ and .97 , respectively), suggesting an absence of change for both groups on these variables. At 6 months, the SWLP + MI group did not differ from the SWLP group on introjected $(p=.57)$ and external regulations $(p=.68)$. Lastly, no significant change was found for the SWLP group on amotivation $(p=.90)$. As compared to those in the SWLP group, participants in the SWLP + MI group reported a significant decrease over time for amotivation $(\mathrm{B}=-0.40, p<.01, d=.44)$. Moreover, they reported a significant lower level of amotivation at 6 months $(\mathrm{B}=0.42, p<.05, d=.29)$ (see Figure 2).

\section{Change in perceived competence}

The analyses revealed a significant increase in perceived competence $(\mathrm{B}=6.90, p<$ $.001, d=.81)$ for the SWLP group. No differential change over time was found for the SWLP + MI group as compared to the SWLP group, suggesting a similar increase for both groups on this variable $(p=.34)$. Moreover, the SWLP + MI group did not differ from the SWLP group on this variable at 6 months $(\mathrm{B}=3.52, p=.50)$.

\section{Differences in perceived autonomy support at the end of the program}

Independent samples $t$-tests revealed a difference between groups in perceived autonomy support at the end of the program $[t(52)=3.02, p<.01, d=.83]$. At 6 months, adolescents in the SWLP + MI condition perceived medical staff as more autonomy supportive $(\mathrm{M}=6.47)$ than those in the SWLP condition $(\mathrm{M}=5.78)$. 
1

2

\section{Discussion}

The primary purpose of this study was to assess the impact of an MI-based intervention in addition to an SWLP on PA and BMI of obese adolescents. The second purpose was to explore some underlying processes involved in these effects, using SDT (Deci \& Ryan, 2002) as an explanatory framework. For this, 54 obese adolescents were randomized into an SWLP or an SWLP + MI condition and then followed over a 6-month period. Effects of MI on PA and BMI

SWLP consisted mainly in (1) providing information intended to increase the value/importance of PA and participants' confidence about their capacities to do it, as well as in (2) developing skills to integrate PA into their lifestyle. Such intervention generally assumes that individuals are ready to make changes. However, many obese teenagers could be ambivalent or resistant to adopting PA in their lifestyle. By contrast, MI is specifically designed to minimize resistance and resolve ambivalence to change. We presumed that in an SWLP, MI could increase participants' motivation toward PA and thus complement the acquisition of behavioral change skills. In other words, an additive effect was presumed because SWLP and MI work through different mechanisms. The results indicate that the addition of MI sessions to an SWLP improved both PA practice and BMI reduction in obese adolescents. Adolescents in the SWLP + MI group reported an increase in self-reported PA by a mean of 33 minutes per day, and of energy expenditure by a mean of 283 kilocalories per day. As compared, participants in the SWLP group remained stable on those variables. These changes in PA for the SWLP + MI group, resulted in a difference between the groups at 6 months suggesting that the addition of 6 MI sessions to the 2 SWLP sessions had a positive impact on PA practice of obese adolescents. The effect sizes in the present study for selfreported PA length $(d=.57)$ and energy expenditure $(d=.38)$ are consistent with those reported among obese adults for $5 \mathrm{MI}$ sessions (spread over the two additional months) after 
120 SWLP sessions spread over the initial four month period $(d=.55)$ (Carels et al. 2007), and

2 larger than those reported for 4 MI sessions combined with 16 SWLP sessions over four

3 months ( $d=-.11$ to -.04) (Befort et al., 2008). Of note, the results for self-reported PA change

4 were confirmed by objective data recorded on a subsample of participants for each group. Past

5 research highlighted the necessity of combining objective and self-reported methods to

6 enhance accuracy of PA measurement (Cliff et al., 2010). From this point, equivalent results

7 stemming from both methods of measurement on the differences of PA change between

8 groups give strong additional credit to the results of this study.

9 Concerning BMI, although the two groups did not differ at 6 months, the changes

10 observed were in the expected direction. Adolescents in the SWLP + MY group reported a

decrease in BMI by a mean of $1.61 \mathrm{~kg} / \mathrm{m}^{2}$. The effect size reported on BMI $(d=.59)$ is

consistent with global mean effect sizes in prior research using MI in addition to an SWLP

among obese adult populations $(d=.40)$ (Armstrong et al., 2011). The absence of difference

between the groups for BMI at 6 months may partially be explained by the small sample size.

throughout an SWLP to improve obesity management among obese adolescents. This study is

17 the first to empirically corroborate the positive impact of MI on pediatric obesity in

complement to an SWLP. More interventions are warranted to identify the optimal dose and

timing of the two parts of the interventions to promote the greatest change in PA among such

\section{Effect of MI on motivational variables}

In order to identify some of the mechanisms involved in the results described above, the present study explored the impact of MI on motivational variables extracted from SDT (Deci \& Ryan, 2002), namely motivational regulations, perceived competence toward PA and 
1 SWLP + MI group reported an increase in integrated and identified regulations as well as a

2 decrease in amotivation over the program. By diminishing amotivation, MI sessions had a

3 positive impact on the "quantity" of motivation (Vansteenkiste \& Sheldon, 2006). Moreover

4 by helping participants to understand why it is personally important and meaningful to

5 participate in PA (i.e., identified regulation) and to value and internalize these personal

6 reasons (i.e., integrated regulation) - two types of autonomous regulation which are

7 particularly important for maintaining sustainable PA behavior among obese adolescents

8 (Gourlan et al., in press) - MI also had an impact on the "quality" of motivation (Vansteekiste

9 \& Sheldon, 2006). In addition, participants in the SWLP + MI group reported higher levels of perceived autonomy support from medical staff. These results confirm that MI is an autonomy supportive counseling method likely to help individual to assimilate in their self, regulation of behavior which are difficult to implement (i.e., PA) but useful for their functioning or wellbeing (Markland et al., 2005). More precisely, the MI core principles (i.e., expressing

major elements of an autonomy supportive climate and processes that promote internalization of behavior (Vansteekiste \& Sheldon, 2006). As it appears necessary to further determine the active components of SDT based interventions (Ng et al., 2012), additional research is needed to more clearly identify which among MI principles operate on perception of autonomy support and the process of internalization (Patrick \& Williams, 2012).

A similar positive change over time for intrinsic motivation and perceived competence was also observed for both groups. This result suggests that MI sessions had no additional effect - above and beyond SWLP - on these variables. Two main reasons may explain these results. Firstly, the impact of the SWLP on perceived competence and intrinsic motivation may have created a "ceiling effect". For example, the SWLP had an impact on perceived competence to a certain level (e.g., $\mathrm{M}=89.32$ and 85.44 for the MI and the SWLP groups, 
1 respectively, at the end of the intervention on a 100 point scale), that may have prevented

2 additional improvement with the MI intervention. A second explanation is that the MI

3 sessions were not sufficient to affect intrinsic motivation and perceived competence. On this

4 point, past research has reported the absence of effect of MI on perceived competence (e.g.,

5 Befort et al., 2008). Future studies should thus address this issue.

Taken as a whole, these results confirmed that while SWLP increases perceived competence (Annesi \& Whitaker, 2010), MI sessions as an adjunct might reduce amotivation and promote autonomy support and autonomous regulation toward a behavior (Markland et al., 2005; Vansteenkiste \& Sheldon, 2006). In other words, these two types of intervention seem to work through different mechanisms (Burke, 2011). While SWLP can provide the necessary skills to complete the target behavior, MI can boost the quantity and quality of motivation for change. Consequently, MI is effective to complete an SWLP by specifically addressing resistance and ambivalence issues about change. While the addition of MI during SWLP generated positive changes in this study, it is important to note that there are several ways of combining or integrating MI and SWLP. While many studies have focused on using MI as a "pretreatment" to build motivation for change prior other treatment (like cognitivebehavioral treatment), this study and others have shown that MI can be valuable during a treatment, because motivational issues can remain a concern throughout the course of such program (Arkowitz, Westra, Miller, \& Rollnick, 2008). Finally, as suggested by some authors (e.g., Flynn, 2011) MI can also serve as an integrative framework in which other interventions can be incorporated. Juxtaposing two techniques can indeed raise several issues if interaction styles are different or if the techniques used are incompatible. For example, "contingent reward" a behavior change technique that is regularly used in the treatment of obesity (e.g., Dombrowski et al., 2012) is rather incompatible with the principles of both MI and SDT (Vansteenkiste, Williams, \& Resnicow, 2012). The high autonomy support score observed in 
1 the SWLP + MI group (i.e., 6.47 on a 7-point scale) shows that this limit was not an issue in

2 this study. However a true integration of MI with other programs implies that healthcare

3 providers incorporate its fundamental skills throughout their interventions, and use it

4 whenever motivational issues arise.

$5 \quad$ Limitations and Perspectives

One limitation of the study concerns the relatively small sample size. Replication with a larger sample is warranted. Another limitation is that the intervention was not time-matched to the control group but rather was provided as an addition to a standard care program that all patients received. It is thus unclear whether the observed benefits in participants who received the SWLP plus MI treatment were due to MI or simply additional therapeutic contact generated by the MI sessions. This limitation is common in many studies that test the effects of MI as a supplement to standard programs (e.g., Carels et al., 2007; Hardcastle et al., 2008). However, it is unlikely that benefit due to additional counselor time provides a full explanation for the observed difference. The positive evolutions of identified, integrated regulations, amotivation and perceived autonomy support observed among MI participants suggest that the higher PA level observed in this group is - at least in part - due to the characteristics of MI. To better calculate the additive effects of MI, future research should use dismantling designs, such as comparing MI + SWLP, and another type of session (e.g., health education; Befort et al., 2008) + SWLP, to SWLP alone, and ideally should control for length of treatment and number of sessions (i.e., using a time-matched control group). A related point of interest would be to investigate if MI is more effective at the beginning or throughout the SWLP, as well as an examination of potential mediators and moderators of outcomes. Finally, the synergistic effect of MI on SWLP (or other programs) could be studied in RCT in which groups of obese participants are assigned either to SWLP delivered by a healthcare provider not trained in MI (i.e., rated low in MITI code) compared to a healthcare provider 
1 who is rated high in MITI code. Future research should also integrate a post intervention

2 follow-up period (e.g., 6 months post intervention) in order to evaluate the maintenance of MI

3 effects over time.

4 As a conclusion, keeping these limitations in mind, results of the present study

5 indicate that MI is an effective intervention that improves PA among obese adolescents

6 compared to a standard weight loss program alone. While an SWLP can provide the necessary

7 skills to adopt behavior change MI can develop motivation for change (Burke, 2011), notably

8 by supporting participants' autonomy perception and promoting autonomous reasons for

9 adopting health behaviors. The relatively low cost-effectiveness associated with MI makes it

10 an attractive method of intervention for the management and prevention of pediatric obesity.

11 In the present investigation, six MI sessions of approximately twenty minutes during six

12 months were sufficient to increase PA and decrease BMI.

13 
2 This research has benefited from the help of the French National Institute of Prevention

3 and Health Education (INPES). The authors would also like to thank Doctor Claudine

4 Perrin for her advice and assistance during the trial.

5

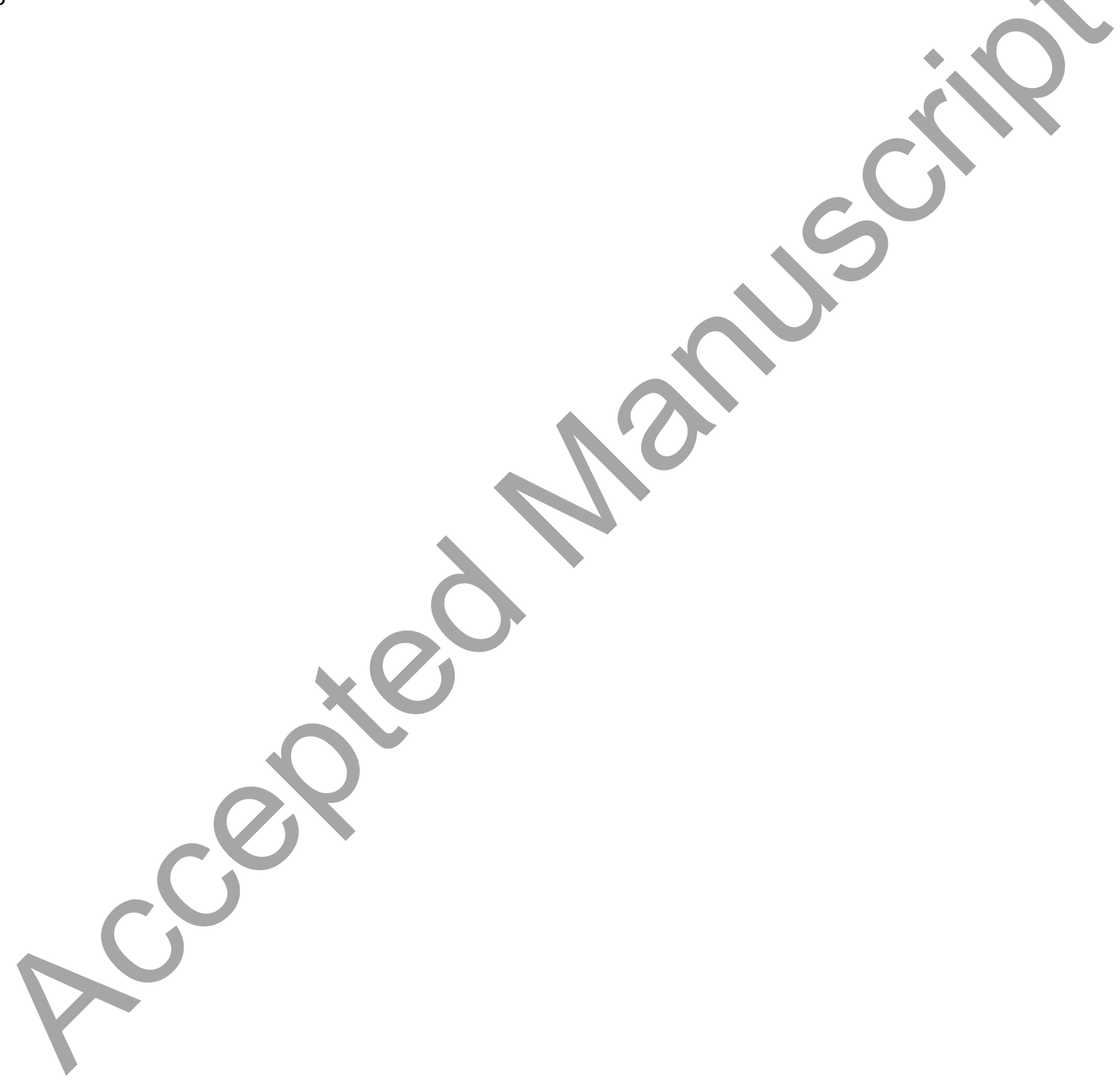


1 Appendix 1. SWLP intervention: behavior change techniques and materials used and a 2 summary of each session.

3 Note. SWLP content is mapped to the behavior change techniques proposed by Michie et al 4 (2011). PA $=$ Physical activity. ${ }^{a}=$ Only PA content is presented in this document, similar 5 behavior change techniques were used for eating behavior.

6 


\begin{tabular}{|c|c|c|}
\hline Session & Behavior change technique & Summary \\
\hline $\begin{array}{l}\text { Session 1: } \\
\text { Evaluating behavior } \\
\text { and providing } \\
\text { information }\end{array}$ & $\begin{array}{l}\text { - Goal setting (behavior) } \\
\text { - Providing information on consequences of } \\
\text { behavior in general } \\
\text { - Prompt self-monitoring of behavior" }\end{array}$ & $\begin{array}{l}\text { The main aim of the first session was to help adolescents to develop intentions } \\
\text { to change (eating behavior, physical activity) a. This session notably consisted } \\
\text { in setting behavioral goals. Based on current recommendations (Blair, } \\
\text { LaMonte, \& Nichaman, 2004) adolescents were instructed to engage in } \\
\text { moderate PA for at least } 30 \text { minutes per day, five or more days per week. In } \\
\text { addition, adolescents were provided with some general information about PA. } \\
\text { More precisely, adolescents were first presented the different "ways" of doing } \\
\text { PA (Donnelly et al., 2009), namely sport activities (e.g., local sport club), } \\
\text { leisure time PA (e.g., doing PA with friends in a playground) and lifestyle PA } \\
\text { (e.g., walking to go to school). In addition, the different "families" of activities } \\
\text { for sport and leisure time PA were presented, namely, team (e.g., football), } \\
\text { artistic (e.g., dance), combat (e.g., judo) and individual activities (e.g., } \\
\text { running). Then, the relationships between PA and health outcomes (e.g., } \\
\text { obesity, cardiovascular disease risk) were presented based on epidemiological } \\
\text { reports (e.g., Stensel, Gorely, \& Biddle, 2008). Lastly, the adolescents were } \\
\text { given a booklet and asked to self-monitor and record their PA over a "typical" } \\
\text { week (i.e., excluding holidays). }\end{array}$ \\
\hline $\begin{array}{l}\text { Session } 2 \text { : } \\
\text { Providing feedback } \\
\text { and giving } \\
\text { instructions to } \\
\text { perform behaviors }\end{array}$ & $\begin{array}{l}\text { - Providing feedback on behavior } \\
\text { - Providing information on consequences of } \\
\text { behavior to the individual (tailored to } \\
\text { obese adolescent) } \\
\text { - Provide information about where and when } \\
\text { to perform the behavior. }\end{array}$ & $\begin{array}{l}\text { The aim of the second session was to help adolescents to adopt behavior } \\
\text { change. Completed self-monitoring records for PA were discussed and } \\
\text { adolescents were given feedback about the differences between their actual } \\
\text { behavior and the recommendations. In order to raise adolescents' awareness } \\
\text { about the importance of adopting behavior change, benefits of PA were } \\
\text { presented. In short, benefits of PA on physical health (e.g., weight loss, health } \\
\text { risks reduction), psychological health (e.g., stress, anxiety), and social aspects } \\
\text { (e.g., making friends) were presented. Lastly, adolescents were told about } \\
\text { where and when to carry out the behaviors. They were instructed to join a local } \\
\text { (or school) sport club and to adopt a more highly active lifestyle (e.g., walking } \\
\text { to go to school, going to a park to walk with the dog). }\end{array}$ \\
\hline
\end{tabular}


Appendix 2. MI intervention: Summary of the different phases, examples of subjects dealt with, open ended questions and techniques used during MI sessions.

Note. $\mathrm{PA}=$ Physical activity, $*=$ When perceived as necessary during intervention.

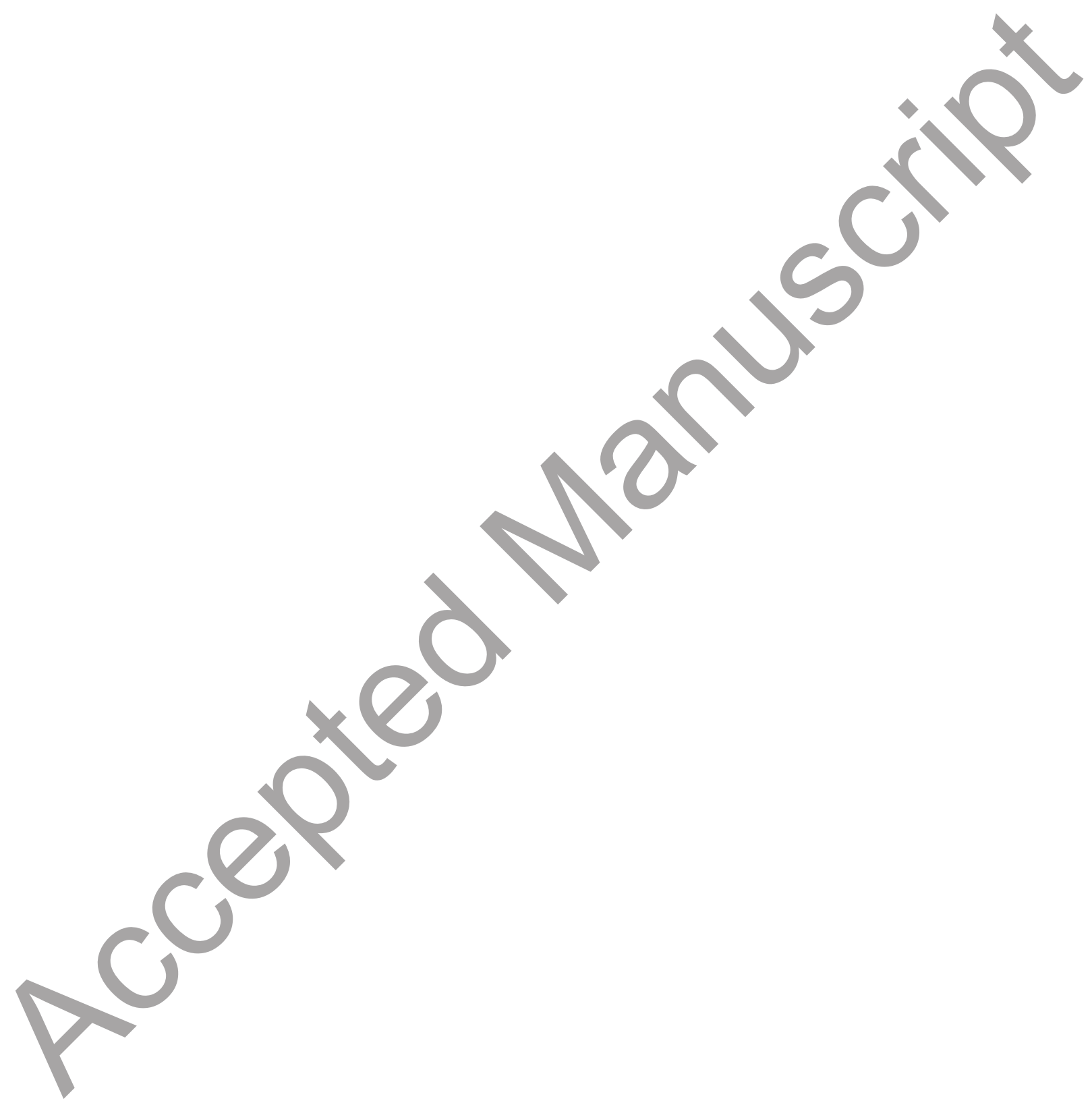




\section{Roll with resistance}

Double reflection: "Ok, on one hand you said that it's important for you to change but on the other hand you also said that it's not an issue at the moment"

Change focus: "If it's not an issue for you at the moment, tell me more about..."

Emphasizing adolescent's control: "It's important that you know that I'm not here to force you to become more active. It's up to you to decide to change or not"

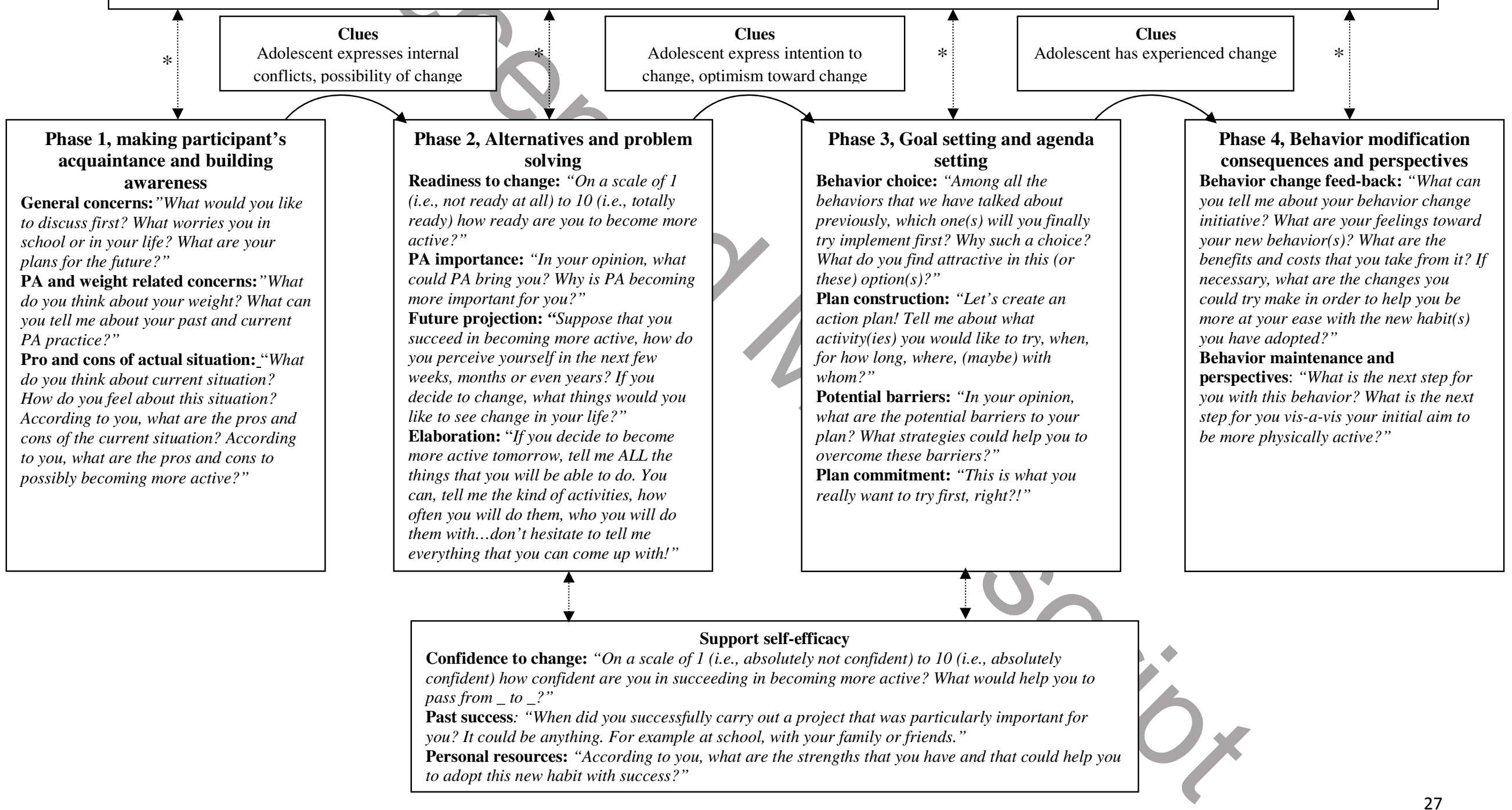




\section{References}

Armstrong, M. J., Mottershead, T. A., Ronksley, P. E., Sigal, R. J., Campbell, T. S., \& Hemmelgarn, B. R. (2011). Motivational interviewing to improve weight loss in overweight and/or obese patients: a systematic review and meta-analysis of randomized controlled trials. Obesity Reviews, 12. doi: 10.1111/j.1467-789X.2011.00892.x

Annesi, J. J., \& Whitaker A, C. (2010). Psychological factors associated with weight loss in obese and severely obese women in a behavioral physical activity intervention. Health Education Behavior, 37 (4), 593-606. doi:10.1177/1090198109331671

Arkowitz, H., Westra, H. A., Miller, W. R., \& Rollnick, S. (2008). Motivational Interviewing in the Treatment of Psychological Problems. New York: Guilford Press.

Bandura, A. (1997). Self efficacy: The exercise of control. New York: Freeman \& Co.

Befort, C. A., Nollen, N., Ellerbeck, E. F., Sullivan, D. K., Thomás, J. L., \& Ahluwalia, J. S. (2008). Motivational interviewing fails to improve outcomes of a behavioral weight loss program for obese african american women: a pilot randomized trial. Journal of Behavioral Medicine, 31, 367-377. doi:10.1007/s10865-008-9161-8

Blair, S. N., LaMonte, M. J., \& Nichaman M, Z. (2004). The evolution of physical activity recommendations: how much is enough? American Society for Clinical Nutrition, 79, 913S920S.

Buchowski, M. S., Townsend, K. M., Chen, K. Y., Acra, S. A., \& Sun, M. (1999). Energy expenditure determined by self-reported physical activity is related to body fatness. Obesity Research, 7, 2333.

Burke, B. L. (2011). What Can Motivational Interviewing Do for You? Cognitive and Behavioral Practice, 18, 74-81. doi:10.1016/j.cbpra.2009.08.004 
Carels, R. A., Darby, L., Cacciapaglia, H. M., Coit, C., Harper, J., Kaplar, M. E.,... Versland, A. (2007). Using motivational interviewing as a supplement to obesity treatment: a stepped-care approach. Health Psychology, 26, 369-374. doi:10.1037/0278-6133.26.3.369

Cliff, D. P., Okely, A. D., Morgan, P. J., Jones R, A., \& Steele J, R. (2010). The impact of child and adolescent obesity treatment interventions on physical activity: a systematic review. Obesity Reviews, 11, 516-530. doi:10.1111/j.1467-789X.2009.00625.x

Cole, T. J., Faith, M. S., Pietrobelli, A., \& Heo, M. (2005). What is the best measure of adiposity change in growing children: BMI, BMI \%, BMI z-score or BMI centile? European journal of clinical nutrition, 59, 419-425. doi:10.1038/sj.ejcn.1602155

Cooper, Z., Fairburn, C., \& Hawker, D. (2003). Cognitive behavioral treatment of obesity: A clinician's guide. New- York: Guilford Press.

Deci, E. L., \& Ryan, R. M. (2002). Handbook of Self-Determination Research. Rochester, New York: University of Rochester Press.

Dombrowski, S. U., Sniehotta, F. F., Johnston, M., Broom, I., Kulkarni, U., Brown, J., . . AraújoSoares, V. (2012). Optimizing acceptability and feasibility of an evidence-based behavioral intervention for obese adults with obesity-related co-morbidities or additional risk factors for co-morbidities: an open-pilot intervention study in secondary care. Patient Education and Counseling, 87,108-119. doi : 10.1016/j.pec.2011.08.003

Donnelly, J. E., Blair, S. N., Jakicic, J. M., Manore, M. M., Rankin, J. W., \& Smith, B. K. (2009). American College of Sports Medicine Position Stand. Appropriate physical activity interyention strategies for weight loss and prevention of weight regain for adults. Medicine \& Science in Sports \& Exercise, 41, 459-471. doi: 10.1249/MSS.0b013e3181949333

Flynn, H. (2011). Setting the stage for the integration of motivational interviewing with cognitive behavioral therapy in the treatment of depression. Cognitive and Behavioral Practice, 18, 46-54. doi: 10.1016/j.cbpra.2009.09.006 
Fortier, M. S., Sweet, S. N., O'Sullivan, T. L., \& Williams, G. C. (2007). A self-determination process model of physical activity adoption in the context of a randomized controlled trial. Psychology of Sport and Exercise, 8, 741-757. doi:10.1016/j.psychsport.2006.10.006

Gilles, A., Cassano, M., Shepherd, E. J., Higgins, D., Hecker, J. E., \& Nangle, D. W. (2008). Comparing active pediatric obesity treatments using meta-analysis. Journal of Clinical Child and Adolescent Psychology, 37, 886-892. doi:10.1080/15374410802359833

Gourlan, M. J., Trouilloud, D. O., \& Sarrazin P, G. (in press). Motivational characteristics of obese adolescents toward physical activity: contribution of self-determination theory. Revue Européenne de Psychologie Appliquée/ European Review of Applied Psychology. Retrieved from http://dx.doi.org/10.1016/j.erap.2013.02.001

Gourlan, M. J., Trouilloud, D. O., \& Sarrazin P, G. (2011). Interventions promoting physical activity among obese populations: a meta-analysis considering global effect, long-term maintenance, physical activity indicators and dose characteristics. Obesity Reviews, 12. e-633-645. doi: 10.1111/j.1467-789X.2011.00874.x

Gross, L., Sallis, J., Buono, M., Roby, J., \& Nelson, J. (1990). Reliability of interviewers using the Seven-Day Physical Activity Recall. Research Quaterly in Exercise and Sport, 61, 321-325. Hettema, J. E., Steele, J. M., \& Miller, W. R. (2005). Motivational Interviewing. Annual Review of Clinical Psychology, 1,91-111. doi: 10.1146/annurev.clinpsy.1.102803.143833

Hardcastle, S., Taylor, A. H., Bailey, M., \& Castle, R. (2008). A randomised controlled trial ofthe effectiveness of a primary health care based counselling intervention on physical activity, diet and coronary heart disease risk factors. Patient Education and Counselling, 70, 31-39. doi:10.1016/j.psychsport.2011.01.001

Lobstein, T., Baur, L., \& Uauy, R. (2004). Obesity in children and young people: a crisis in public health. Obesity Reviews, 5, 4-104. doi:10.1111/j.1467-789X.2004.00133.x 
Lundahl, B., \& Burke, B. L. (2009). The effectiveness and applicability of motivational interviewing: a practice-friendly review of four meta-analyses. Journal of Clinical Psychology, 65, 1232-1245. doi: $10.1002 /$ jclp. 20638

Lundahl, B. W., Kunz, C., Brownell, C., Tollefson, D., \& Burke, B. L. (2010). A meta-analysis of motivational interviewing: Twenty-five years of empirical studies. Research on Social Work Practice, 20, 137-160. doi: 10.1177/1049731509347850

MacDonell, K., Brogan, K., Naar-King, S., Ellis, D., \& Marshall, S. (2012). A pilot study of motivational interviewing targeting weight-related behaviors in overweight or obese African American adolescents. Journal of Adolescent Health, 50, 201-203. doi:10.1016/j.jadohealth.2011.04.018

Markland, D., \& Tobin, V. (2004). A modification to the Behavioural Regulation in Exercise Questionnaire to include an assessment of amotivation. Journal of Sport and Exercise Psychology, 26, 191-196.

Markland, D., Ryan, R. M., Tobin, V. J., \& Rollnick, S. (2005). Motivational interviewing and SelfDetermination Theory. Journal of Social and Clinical Psychology, 24, 811-831. doi:10.1521/jscp.2005.24.6.811

Michie, S., Ashford, S., Sniehotta F, F., Dombrowski, S. U., Bishop, A., \& French D, P. (2011). A refined taxonomy of behaviour change techniques to help people change their physical activity and healthy eating behaviours: the CALO-RE taxonomy. Psychology and Health, 26, 1479-1498. doi: $10.1080 / 08870446.2010 .540664$

Miller, W. R., \& Rollnick, S. (2002). Motivational Interviewing: Preparing People for Change. (2nd ed). New York: Guilford Press.

Miller, W. R., \& Rollnick, S. (2009). Ten Things that Motivational Interviewing Is Not. Behavioural and cognitive psychotherapy, 37, 129-140. doi: 10.1017/S1352465809005128 
Ng, J., Thogersen-Ntoumani, E. C., Ntoumanis, N., Deci, E. L., Ryan, R., Duda, J., \& Williams, G. (2012). Self-Determination Theory applied to health contexts: A meta-analysis. Perspectives on Psychological Science. 7, 325-340. doi: 10.1177/1745691612447309

Olds, T. S., Ferrar, K. E., Schranz, N. K., \& Maher, C. A. (2011). Obese adolescents are less active than their normal-weight peers, but wherein lies the difference? Journal of Adolescent Health, 48, 189-195. doi:10.1016/j.jadohealth.2010.06.010

Parizkova, J., \& Hills, A. (2001). Childhood obesity: prevention and management . Boca Rotan, Florida: CRC Press.

Patrick, H., \& Williams, G. C. (2012). Self-Determination Theory: its application to health behavior and complementarity with motivational interviewing. International Journal of Behavioral Nutrition and Physical Activity, 9(18), 1-12. doi:10.1186/1479-5868-9-18

Pereira, M. A., FitzGerald, S. J., Gregg, E. W., Joswiak, M.L., Ryan, W. J., Suminski, R. R., ... Zmuda, J. M. (1997). A Collection of physical activity questionnaires for health-related research. Medicine and Science in Sports and Exercise, 29, S1-205 .

Rasbash, J., Brown, W., Healy, M., Cameron, B., \& Charlton, C. MLwiN Version 1.1.

Reilly, J. J. (2007). Childhood obesity: an overview. Children \& Society, 21, 390-396. doi:10.1111/j.1099-0860.2007.00092.x

Resnicow, K., Davis, R., \& Rollnick, S. (2006). Motivational Interviewing for pediatric obesity: conceptual issues and evidence review. Journal of the American Dietetic Association, 106, 20242033. doi:10.1016/j.jada.2006.09.015

Rollnick, S., Miller, W. R., \& Butler, C. C. (2008). Motivational interviewing in health care, helping patients change behavior. New York: The Guilford Press.

Silva, M. N., Vieira P, N., Coutinho, S. R., Minderico, C. S., Matos, M. G., Sardinha, L. B., \& Teixeira, P. J (2010). Using Self-Determination Theory to promote physical activity and weight 
control: a randomized controlled trial in women. Journal of Behavioral Medicine, 33, 110-122. doi:10.1007/s10865-009-9239-y

Steele, F. (2008). Multilevel models for longitudinal data. Journal of the Royal Statistical Society, 171, 5-19. doi:10.1111/j.1467-985X.2007.00509.x

Stensel, D. J., Gorely, T., \& Biddle, S. J. (2008). Youth health outcomes. In A. L. Smith, \& S. J. Biddle (Eds.), Youth physical activity and sedentary behavior: Challenges and solutions (pp. 31-57). Champaign, IL: Human Kinetics.

Trost, S. G., McIver, K., \& Pate, R. (2005). Conducting accelerometer-based activity assessments in field-based research. Medicine and science in sports and exercise, 37, S531-543. doi:10.1249/01.mss.0000185657.86065.98

van Keulen, H. M., Mesters, I., Ausems, M., van Breukelen, G., Campbell, M., Resnicow, K.,... de Vries, H. (2011). Tailored print communication and telephone motivational interviewing are equally successful in improving multiple lifestyle behaviors in a randomized controlled trial. Annals of Behavioral Medicine , 41,104-118. doi:10.1007/s12160-010-9231-3

Vansteenkiste, M., \& Sheldon, K. M. (2006). There's nothing more pratical than a good theory: Integrating motivational interviewing and Self-Determination Theory. British Journal of Clinical Psychology , 45, 63-82. doi:10.1348/014466505X34192

Vansteenkiste, M., Williams, G. C., \& Resnicow, K. (2012). Toward systematic integration between self-determination theory and motivational interviewing as examples of top-down and bottomup intervention development: autonomy or volition as a fundamental theoretical principle. International Journal of Behavioral Nutrition and Physical Activity, 9, 1-11. doi: $10.1186 / 1479-5868-9-23$

Welk, G. J., McClain, J. J., Eisenmann, J. C., \& Wickel, E. E. (2007). Field validation of the MTI Actigraph and BodyMedia armband monitor using the IDEEA monitor. Obesity, 15, 918-928. doi:10.1038/oby.2007.624 
Westra, H. A., \& Arkowitz, H. (2011). Integrating Motivational Interviewing With Cognitive Behavioral Therapy for a Range of Mental Health Problems. Cognitive and Behavioral Practice, 18, 1-4.

Wilson, P.M., Rodgers, W.M., Loitz, C.C., \& Scime, G. (2006). "It's Who I Am...Really!" The Importance of Integrated Regulation in Exercise Contexts. Journal of Applied Biobehavioral Research, 11, 79-104. doi 10.1111/j.1751-9861.2006.tb00021.x 


\section{Footnotes}

${ }^{1}$ Tables including results from all the MLM analyses are available from the first author on request.

${ }^{2}$ Objective and self-reported PA appeared significantly correlated both at baseline and 6 months for PA length ( $r=.41$ and $r=.53, p s>.01$, respectively) and energy expenditure $(r=.36$ and $r=.47, p s<.05$, respectively). 
Table 1.

Reliability analysis (Cronbach's coefficient alpha), Means (M) and Standard Deviations (SD) for psychosocial variables, BMI, self-reported and objective PA at each measurement point

\begin{tabular}{|c|c|c|c|c|c|c|c|c|c|c|c|c|c|c|c|c|}
\hline \multirow[b]{3}{*}{ Variables } & \multirow[b]{3}{*}{ Range } & \multirow[b]{3}{*}{ Alpha } & \multicolumn{4}{|c|}{ Month 0} & \multicolumn{5}{|c|}{ Month 3} & \multicolumn{5}{|c|}{ Month 6} \\
\hline & & & \multirow{2}{*}{\multicolumn{2}{|c|}{$\begin{array}{c}\text { SWLP + MI group } \\
M \quad(\mathrm{SD})\end{array}$}} & \multicolumn{2}{|c|}{ SWLP group } & \multirow[b]{2}{*}{ Alpha } & \multicolumn{2}{|c|}{ SWLP + MI group } & \multicolumn{2}{|c|}{ SWLP group } & \multirow[b]{2}{*}{ Alpha } & \multicolumn{2}{|c|}{ SWLP + MI group } & \multicolumn{2}{|c|}{ SWLP group } \\
\hline & & & & & M & (SD) & & M & (SD) & M & (SD) & & M & (SD) & M & (SD) \\
\hline Autonomy support & $1-7$ & & & & & & & & & & & .77 & 6.47 & $(0.57)$ & 5.78 & $(1.02)$ \\
\hline Perceived competence & $0-100$ & .92 & 80.67 & $(23.55)$ & 71.63 & $5.98)$ & .85 & 84.71 & $(17.07)$ & 79.31 & $(24.08)$ & .73 & 89.32 & $(13.55)$ & 85.44 & (15) \\
\hline Amotivation & $1-7$ & .69 & 1.89 & $(1.26)$ & & & .71 & 1.72 & $(0.64)$ & 1.62 & $(0.67)$ & .75 & 1.3 & $(0.45)$ & 1.78 & $(0.80)$ \\
\hline External regulation & $1-7$ & .70 & 2.25 & $(1.08)$ & 2.26 & & & 1.89 & $(1.14)$ & 2.28 & $(1.24)$ & .71 & 2.17 & $(1.21)$ & 2.16 & $(0.99)$ \\
\hline Introjected regulation & $1-7$ & .78 & 3.22 & $(1.07)$ & 3.27 & & .74 & 3.23 & $(1.37)$ & 3.16 & $(1.44)$ & .78 & 3.08 & $(1.41)$ & 3.36 & $(1.33)$ \\
\hline Identified regulation & $1-7$ & .69 & 4.88 & $(1.41)$ & 4.91 & $(1.07)$ & & 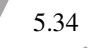 & $(1.11)$ & 4.92 & $(0.83)$ & .73 & 5.57 & $(0.94)$ & 4.93 & (1.16) \\
\hline Integrated Regulation & $1-7$ & .78 & 4.09 & (1.16) & 4.12 & $(1.12)$ & & & $(1.31)$ & 4.31 & $(1.35)$ & .77 & 4.82 & $(1.12)$ & 4.06 & $(1.16)$ \\
\hline Intrinsic Motivation & $1-7$ & .74 & 5.46 & $(1.12)$ & 5.02 & $(1.10)$ & .77 & & & 5.22 & $(1.36)$ & .79 & 5.95 & $(0.77)$ & 5.47 & $(1.27)$ \\
\hline Self-reported PA length & & & 0.74 & $(0.44)$ & 1.07 & $(0.65)$ & & & & 1.05 & $(0.76)$ & & 1.30 & $(0.82)$ & 0.99 & $(0.62)$ \\
\hline \multicolumn{17}{|l|}{ Self-reported energy } \\
\hline expenditure & & & 282.70 & $(158.23)$ & 419.90 & (258.99) & & 399.91 & & & (304.07) & & 565.33 & $(320.60)$ & 437.72 & $(258.42)$ \\
\hline Objective PA length & & & 0.66 & $(0.25)$ & 1.12 & $(0.67)$ & & & & & & & 2.01 & $(0.85)$ & 1.62 & $(0.53)$ \\
\hline $\begin{array}{l}\text { Objective energy } \\
\text { expenditure }\end{array}$ & & & 334 & $(66.93)$ & 297.22 & 106.13) & & & & & & & 750.5 & $(346.24)$ & 358.55 & $(272.47)$ \\
\hline BMI & & & 29.56 & $(4.75)$ & 29.59 & $(5.92)$ & & 28.42 & $(4.63)$ & 29.9 & $(5.9$ & & 27.95 & $(4.53)$ & 29.71 & $(5.96)$ \\
\hline
\end{tabular}

Notes: SWLP group= Standard Weight Loss Program group $(\mathrm{n}=28)$. SWLP + MI group= Standard Weight Loss Program plus Motivational Interviewing group $(\mathrm{n}=26)$.

$\mathrm{PA}=$ Physical activity. $\mathrm{M}=$ Mean. $\mathrm{SD}=\mathrm{Standard}$ Deviation. $\mathrm{PA}$ length is in hours per day. Energy expenditure is in kilocalories per day. 


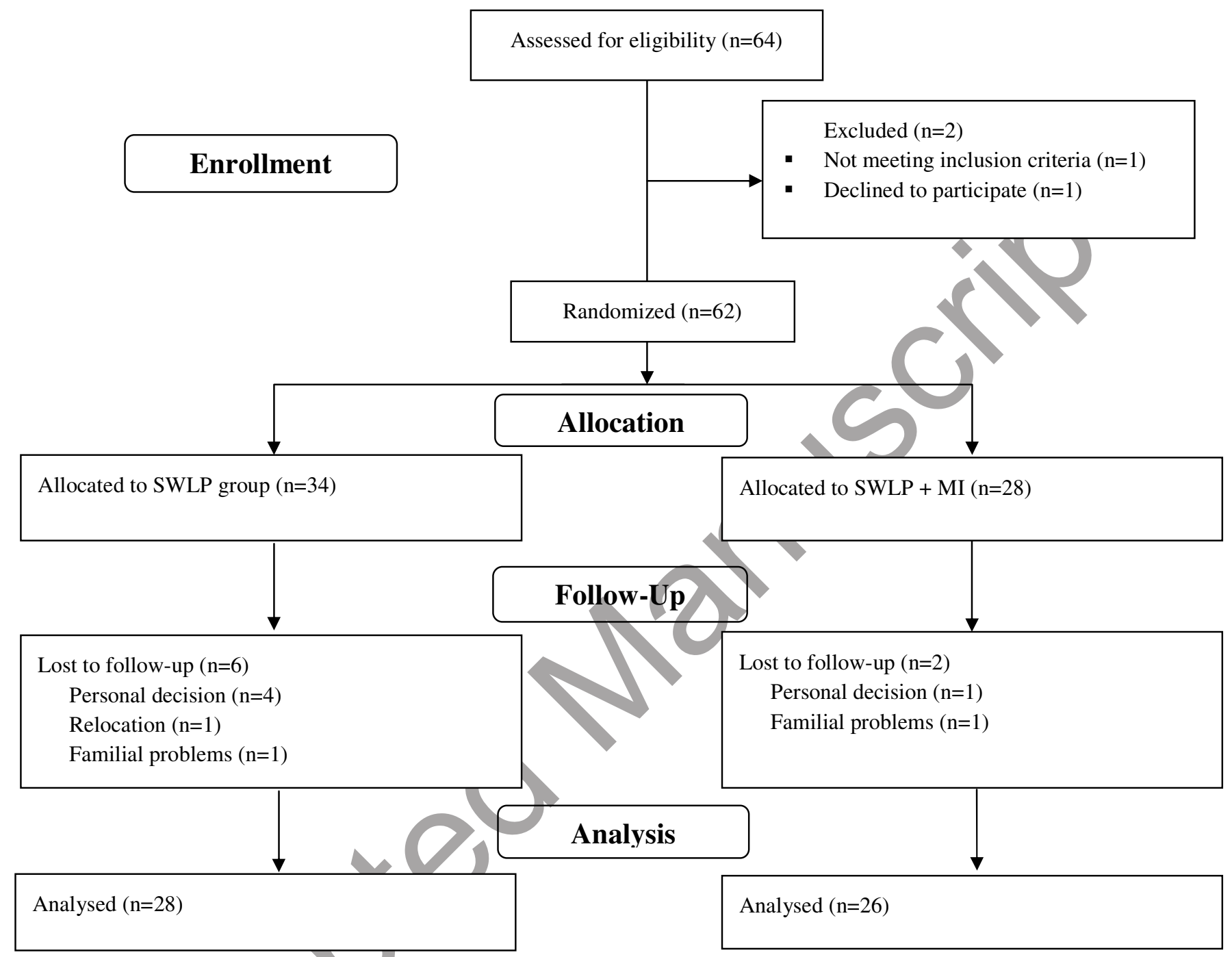

Figure 1. CONSORT flowchart of participants.

Note. SWLP $=$ Standard weight loss program, MI= Motivational interviewing. 

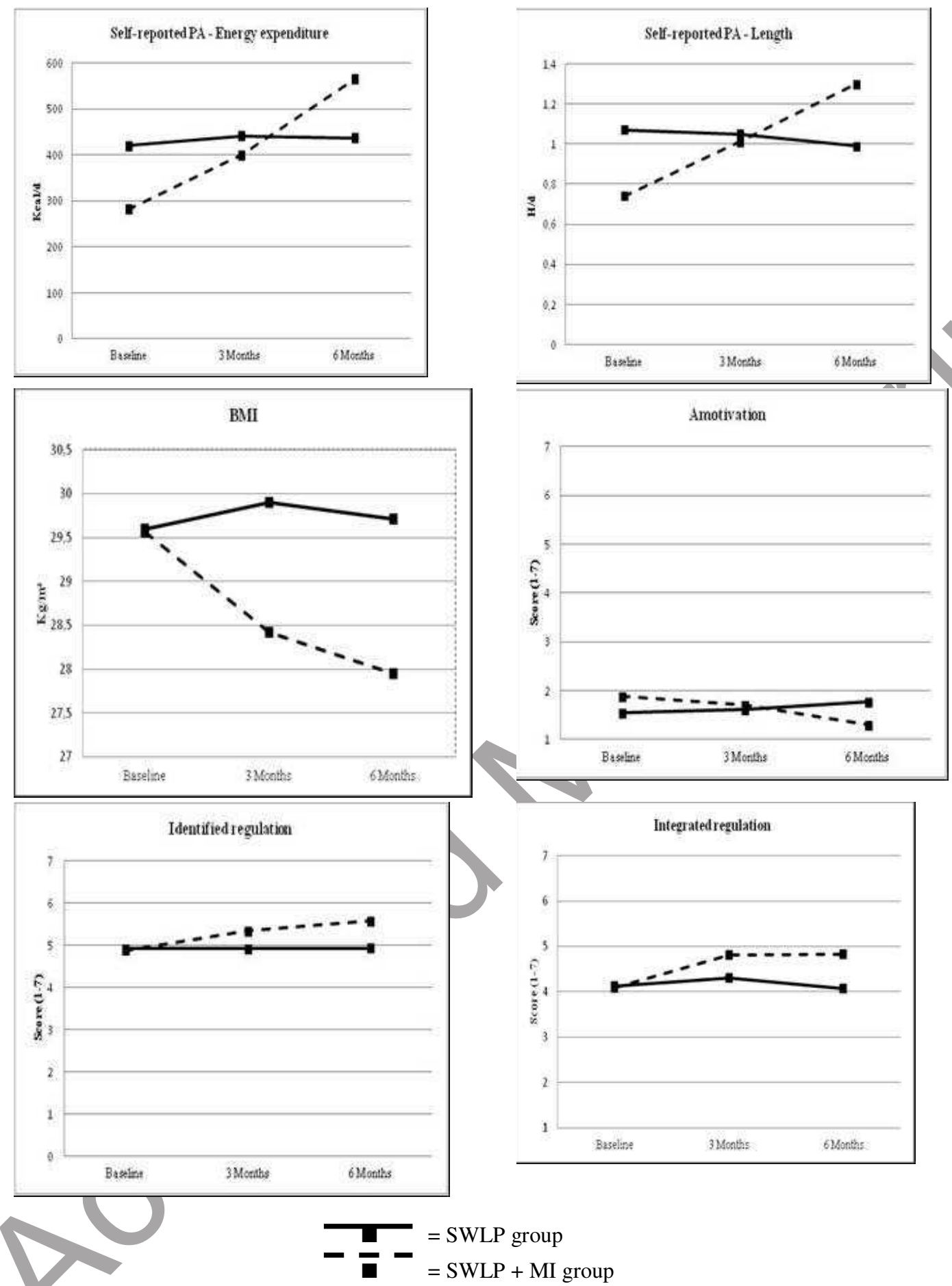

Figure 2. Trajectories of participants in the MI and SWLP groups for self-reported PA energy expenditure, PA length, BMI, amotivation, identified regulation and integrated regulation.

Note. $\mathrm{PA}=$ Physical activity, $\mathrm{BMI}=$ Body mass index, $\mathrm{H} / \mathrm{d}=$ Hours per day, $\mathrm{Kcal} / \mathrm{d}=\mathrm{Kilocalories}$ per day, $\mathrm{Kg} / \mathrm{m}^{2}=$ Kilograms per square meter 